\title{
Microvesicles in Gliomas and Medulloblastomas: An Overview
}

\author{
Muhammad Nawaz, Farah Fatima, Bruna Riedo Zanetti, Isabela de Lima Martins, \\ Nathalia Lopes Schiavotelo, Niele Dias Mendes, Renata Nacasaki Silvestre, Luciano Neder* \\ Department of Pathology and Forensic Medicine, Faculty of Medicine of Ribeirão Preto, University of São Paulo, São Paulo, Brazil. \\ Email: neder@fmrp.usp.br
}

Received November $23^{\text {rd }}, 2013$; revised December $20^{\text {th }}$, 2013; accepted December $28^{\text {th }}, 2013$

Copyright (C) 2014 Muhammad Nawaz et al. This is an open access article distributed under the Creative Commons Attribution License, which permits unrestricted use, distribution, and reproduction in any medium, provided the original work is properly cited. In accordance of the Creative Commons Attribution License all Copyrights @ 2014 are reserved for SCIRP and the owner of the intellectual property Muhammad Nawaz et al. All Copyright (C) 2014 are guarded by law and by SCIRP as a guardian.

\begin{abstract}
Microvesicles (MVs) or shedding membrane vesicles have recently been described as a novel model of intercellular communication. Previously, MVs were considered as unnecessary or secreted cellular debris, but MVs have lately been described as having roles in a variety of biological functions, such as cell homeostasis and the cellular processes involved in the oncogenesis of many types of tumors. Carrying several key molecules that contribute to tumor development and progression, similar to mRNAs, microRNAs and other non-coding RNAs, DNA and even small proteins, MVs can be considered as a ubiquitous form of novel cell communication that is present in most somatic cells. Although tumor-derived MVs have been demonstrated in different types of cancers, the literature data on MVs in primary central nervous system (CNS) tumors are relatively scarce. In this review, we address the involvement of MVs in diffuse astrocytomas, particularly glioblastomas, as well as oligodendrogliomas and medulloblastomas. We placed particular focus on the cellular crosstalk between tumor and "normal" cells, the putative mechanisms how the tumor microenvironment is modulated and the spread of aggressive phenotypes. Additionally, a better understanding of the participation of tumor-derived MVs in the regulation of key cancer pathways will offer new insights into tumor pathogenesis and the mechanisms of multidrug resistance, and may help to develop new strategies for novel therapies against these infiltrative CNS tumors.
\end{abstract}

\section{KEYWORDS}

Microvesicles; Exosomes; Microparticles; Gliomas; Glioblastomas; Medulloblastomas; Oligodendrogliomas; Review

\section{Introduction}

Gliomas are the most common type of primary malignant brain tumor, accounting for $80 \%$ of brain tumor cases, and comprise tumors of astrocytic, oligodendroglial and ependymal differentiation at different grades of malignancy. The last World Health Organization (WHO) classification for tumors of the Central Nervous System (CNS) categorizes gliomas into four histological grades according to proliferative activity, tumor invasiveness, anaplasia, presence of necrosis and/or abnormal vasculature, which is defined as microvascular proliferation [1]. In general, gliomas are most common in the sixth throu-

\footnotetext{
"Corresponding author.
}

gh eighth decades of life, though they can be observed at any age, including children and even newborns [2]. Grade I gliomas are considered benign, non-infiltrative tumors and therefore, are susceptible to surgical cure. In contrast, diffuse astrocytomas (Grade II, III or IV) are considered malignant, mainly due to their active brain invasiveness, hindering complete tumor resection or surgical cure. Grade IV astrocytomas or glioblastomas (GBMs) are the most prevalent and lethal glioma of adulthood. Due to the rapid growth of GBMs and their high resistance to current therapies, GBM patients have a dismal prognosis, with a median survival rate of $12-14$ months after diagnosis [2]. 
Box 1. Glossary.

Microvesicles: a collective term used for mix population of vesicles comprised of exosomes, microparticles, Golgi vesicles, non-secretory vesicles and ectosomes.

Exosomes: a subtype of microvesicle that is sorted in multivesicular late endosomes (MVEs) and shed following the fusion of MVEs with the cell membrane.

Microparticles: a subtype of microvesicle that buds off from the outward protrusions of specific regions of the cell membrane (mainly lipid rafts) and is shed outwardly.

Ectosomes: microvesicles produced by the direct release of the plasma membrane. This term sometimes overlaps with microparticles, but ectosomes are commonly linked to immune cells, whereas microparticles bud off from specific regions of the cell membranes.

Shed vesicles: a broad term used for almost all types of vesicles that are shed to the outside environment, as microparticles and exomes, even though their origins are different.

MVEs: multivesicular late endosomes are endosomal sacs that contain large numbers of exosomal vesicles.

MVBs: multivesicular bodies are a type of late endosome containing internal vesicles formed after the inward budding of the outer endosomal membrane. The contents of MVBs are then released into the lysosome lumen (UNIPROT).

ESCRTs: endosomal sorting complexes required for transport are components of the system involved in the sorting of MVEs and the production of exosomes.

Medulloblastomas (MBs) are embryonic tumors of the cerebellum, one of the most common CNS tumors in childhood and a major cause of cancer-related deaths in pediatric patients $[3,4]$. Standard treatment includes gross total resection, radiation therapy (RT) and adjuvant chemotherapy. Although MBs have a tendency to metastasize via the cerebrospinal fluid (CSF), $60 \%$ to $70 \%$ of patients with high-risk disease attain long-term, eventfree survival; however, young children ( $<3$ years of age) and patients with metastatic tumors have a dismal prognosis.

One of the key features of diffuse gliomas (Grades II to IV) and MBs is the capacity of their tumor cells to actively invade and spread throughout the brain parenchyma and CSF pathway, respectively. Historically, the main proposed mechanisms suggest that cancer cells modulate their local environment through direct cellto-cell interactions via tunneling nanotubules and the release of soluble factors. However, more recently, microvesicles have been implicated in a novel model of intercellular communication in these tumors [5-7].

Microvesicles (MVs) are membrane vesicles that are shed form different types of cells and are composed of small lipid bilayer bodies of different sizes [8]. In the past, MVs were considered as unnecessary or secreted cellular debris. However, recent findings have highlighted the neglected roles of MVs and have shown their participation in a variety of biological functions, such as cell homeostasis, physiology and cellular processes leading to the pathogenesis of various cancers, including gliomas.
Most somatic cells use MVs ubiquitously to communicate with neighboring cells under both normal and pathologic conditions. The functional activity of MVs is determined by their cellular origin and site of release. Additionally, MVs are capable of modulating the surrounding extracellular environment by carrying several key molecules related to tumor development and progression, such as angiogenic proteins, mRNAs, microRNAs and other small non-coding RNAs, and even DNA. In fact, tumor-derived MVs have been shown to be involved in the immune response, tumor invasiveness and progression, metastasis, and multidrug resistance [7,9-12].

\section{Biogenesis of Microvesicles}

Based on their size and mechanism of release, membrane vesicles can be categorized into three types: exosomes (50 - $100 \mathrm{~nm}$ ), microparticles (100 - $1000 \mathrm{~nm}$ ) and apoptotic bodies [13]. In fact some authors have proposed that MVs comprise a mixed population of microparticles and exosomes $[7,8]$. Microvesicles can be formed by different pathways, namely through apoptotic disaggregation or endocytosis, followed by exocytosis and the formation of exosomes [8,14-16]. Although used interchangeably by some authors, exosomes and microparticles are quite different structures based on their origin, shape and mode of formation, as shown in Table 1.

The precise cellular mechanisms that regulate microvesicle packing and biogenesis are not yet fully understood. However, it is well known that the biogenesis and shedding of MVs are tightly regulated processes. Basically, MV biogenesis depends on the type of membrane vesicles of which they are composed, i.e., microparticles or exosomes.

Microparticles are generated through the cellular trafficking of bioactive molecules to the cell surface using intracellular membranes. This process leads to cell membrane protrusion, budding and, finally, the detachment of spherical fragments from specific regions of the cell surface known as lipid rafts (Figure 1(a)).

Conversely, the biogenesis of exosomes uses the multivesicular body (MVB) sorting pathway in which proteins and lipids are initially destined for degradation in lysosomes. In a simplistic view, exosome formation is linked to cellular endocytosis, whereby multivesicular late endosomes (MVEs) initially destined for digestion in lysosomes are recycled back to the extracellular environment after fusion with the cell membrane and shedding (Figure 1(b)).

The load of MVEs appears to be chosen on the basis of both cis-acting sorting signals, such as ubiquitin, and trans-acting factors, such as the endosomal sorting complex required for transport (ESCRT) machinery $[17,18]$. Trakjovic and colleagues described an alternative pathway for the sorting of cargo into MVEs, which is inde- 
Table 1. Main features of microparticles and exosomes.

\begin{tabular}{|c|c|c|}
\hline & Microparticles & Exosomes \\
\hline Origin & Plasma membrane & Endosomes \\
\hline $\begin{array}{c}\text { Mode of } \\
\text { formation }\end{array}$ & Outward budding & $\begin{array}{l}\text { Endocytosis and } \\
\text { Exocytosis }\end{array}$ \\
\hline Size & $100-1000 \mathrm{~nm}$ & $50-100 \mathrm{~nm}$ \\
\hline Shape/morphology & Irregular vesicles & Cup-shaped vesicles \\
\hline $\begin{array}{c}\text { Markers and } \\
\text { surface receptors }\end{array}$ & $\begin{array}{l}\text { Integrins, Selectins } \\
\text { (CD62), } \\
\text { CD40 ligand, CD133 }\end{array}$ & $\begin{array}{c}\text { Tetraspanins (CD9, } \\
\text { CD63), } \\
\text { Alix, TSG101, ESCRT }\end{array}$ \\
\hline Lipids & $\begin{array}{l}\text { Phosphatidylserine, } \\
\text { lipid rafts }\end{array}$ & $\begin{array}{c}\text { Cholesterol, } \\
\text { sphingomyelin, } \\
\text { ceramide, } \\
\text { phosphatidylserine }\end{array}$ \\
\hline
\end{tabular}

Cytoskeleton and Actin, myosin, tubulin, RAB family, signaling factors ${ }^{*} \quad$ transmembrane proteins,

"Present in both microparticles and exosomes.

pendent of the ESCRT machinery but is instead dependent on raft-based microdomains [19]. Subsequently, these ceramide-rich microdomains can promote the domain induced budding of exosome vesicles through the lateral segregation of cargo within the endosomal membrane.

Interestingly, MV uptake and trafficking are not passive mechanisms. The MV cargo may be quite different from the material of the parental cell, as the intracellular content of MVs is selectively enriched rather than passively sequestered. More recently, Li and colleagues reported in an elegant study that, although microRNAs are relatively depleted in U251 glioma cell MVs, some microRNAs (miR-451 and other non-coding RNAs), repeated-derived small RNAs, and even vault RNAs are enriched in those MVs [7].

Lastly, based on the observations of Rankin and Wordeman [20], we may speculate that the spindle rocking and cytoskeleton machineries, which are escorted by clathrin, tubulin, actin and myosin molecules, may traffic and propel biomolecules toward the plasma membrane in abnormally proliferating cells where they may initiate membrane blebs at lipid rafts, resulting in the budding and cell extrusion of MVs. However, this mechanism has not been demonstrated to date.

\section{Components of Microvesicles}

In a pioneering study, Valadi and colleagues reported that exosomes released from human and murine mast cell lines contain mRNAs and miRNAs [9]. In 2008, Skog et al. concluded that GBM cells also release MVs loaded with non-coding RNAs and mRNAs [12]. Other studies have formed a consensus that the content of MVs and the biological functions depend on the cells of origin. In fact, MVs derived from donor cells contain heterogeneous biomolecules, which include a plethora of genomic com-

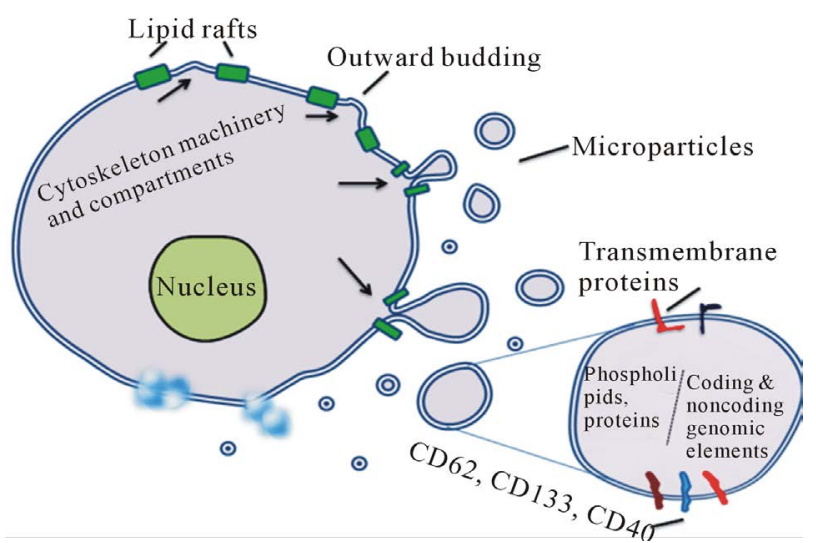

(a)

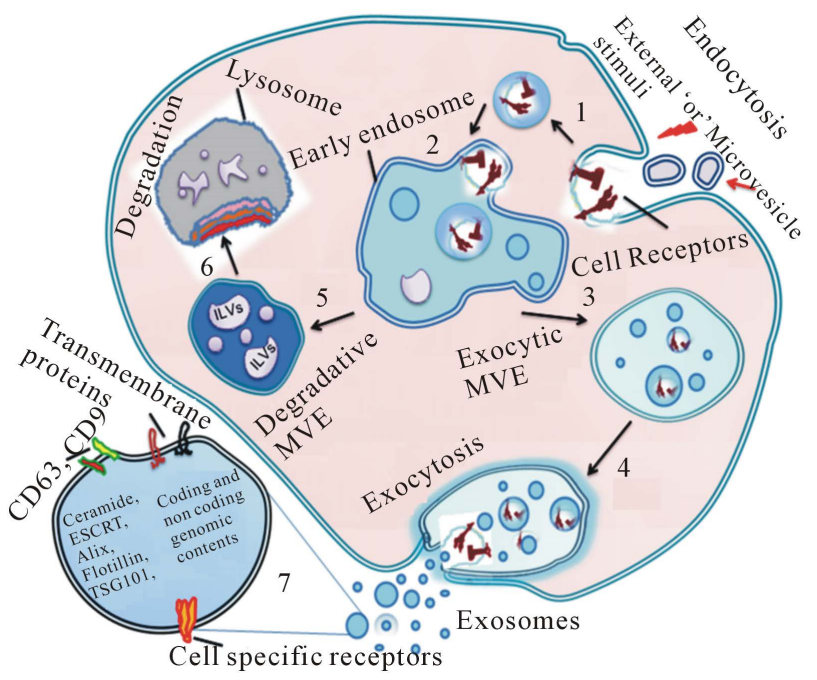

(b)

Figure 1. Schematic representation of microvesicle (MV) biogenesis. (a) Microparticle formation: Discrete regions of plasma membrane bud off small vesicles. Green bars represent lipid rafts in which MV budding initiate. Arrows represent the trafficking of membrane elements and cytosolic components. In order to adjust or respond abnormal environment of the cell, the cytoskeleton machinery may contribute for these minute blebs. Magnified circle exhibits the enlarged view of a typical shed vesicle with its internal content and surface markers. (b) Exosome formation: 1) Initiation of endocytosis either in response to external stimuli or by interaction of other MVs into plasma membrane receptors. 2) Development of early endosome to sort endocytic material that further results into formation of two types of multivesicular late endosomes (MVEs), namely "degradative" MVEs and "exocytic" MVEs. 3) Exocytic MVEs are recycled back and fused with plasma cell membrane. 4) Exocytosis followed by the fusion of MVEs with plasma cell membrane and exosomes are released to the extracellular environment. 5) In degradative MVEs proteins and lipids assigned for lysosomal degradation by ubiquitin are incorporated into intraluminal vesicles (ILVs) of degenerative MVEs. 6) Delivery of degradative cargo to lysosome for enzymatic digestion. 7) Enlarged view of a typical exosome with its internal content and surface markers. Ceramide and ESCRT are critical for endosome sorting to MVEs. 
ponents: mRNAs, microRNAs, small non-coding RNAs, tRNAs, vault RNAs, as well as intronic regions of the genome, most of which are of unknown function, and even transposable elements. Microvesicle cargo may also be packed with proteomic contents, cell-surface receptors, signaling proteins, cytoskeletal components and intracellular signaling proteins, including transcriptional regulators [21], EGFRvIII, and EGF [22,23]. These results are very suggestive the involvement of MVs in cancer (Table 2) [7,10-12].

Some MVs may exhibit highly selective and customized microRNA packing. Microvesicles from the HEK293 embryonic kidney cell line are selectively packed with miR-451, suggesting the specific packing of this microRNA [15]. Similarly, MVs from breast cancer cell lines have also been found to selectively release miR1246 [24] and glioma-derived MVs exhibit the selective packing of miR-21, an oncomir that has been consistently overexpressed in several cancers [7]. Altogether, these data are consistent with the concept that MV packing is not a random process but is rather a highly customized and specific way for tumor cells to communicate with each other and with stromal cells to modulate their microenvironment.

\section{MVs, Mediators of Intercellular Communication and Genetic Transfer}

Shed MVs are capable of interacting with a variety of cell types and have emerged as messengers of cross-talk and vehicles of horizontal genetic exchange between different types of cells (Figure 2). Therefore, tumor cells can modulate their environment by shedding MVs, which can fuse and transfer a cargo of bioactive molecules to stromal cells $[9,12,22,25]$. In addition, MVs released by neural stem cells have been described as displaying intercellular communication, as they exchange non-secreted proteins and genetic information [26]. The specificity of MVs for target cells may be guided by their distinct membrane surface molecules, such as adhesion molecules, surface receptors, integrins and ligands (Table 1), which can influence their capture by target cells $[27,28]$.

These surface interactions enable MVs to be coupled to receptor molecules on target cells and/or to transfer their contents directly to recipient cells in a phagocytic manner. The incorporation of MVs into the recipient cell appears to constitute a ubiquitous biological event, but there could be some discrete mechanisms for distinct tissues or cell types, which are not yet fully understood.

We have also speculated on the conceivable participation of transcytosis in tumor cells, whereby biomolecules can be conveyed from one side to the other side of a cell by membrane-bound vesicular carriers to adjust the composition of two dissimilar microenvironments. Although the mechanism of transcytosis has been studied under different pathologic conditions [29-31], it has not yet been described in gliomas.

\section{Epigenetic Reprogramming of Recipient Cells}

Ratajczak and colleagues were the first to show that MVs can induce the reprogramming of target cells, which occurs when normal cells are exposed to cancer cell-derived MVs and acquire a transformed phenotype [25,41]. Furthermore, MVs play critical roles in modulating stromal cells to transform the tumor microenvironment to support tumor cell proliferation, invasion and angiogenesis, and decrease immune responses [16]. Microvesicles may play important roles in tissue homeostasis and in tumor cell orientation in their microenvironment. For instance, it was shown that, when glioblastoma MVs loaded with mRNAs were taken up by recipient cells, these cells changed their translational phenotype [12]. Similarly, MVs derived from embryonic stem cells and glioma cells can affect gene expression in recipient cells by transferring microRNAs, non-coding RNAs and small RNAs $[7,42]$. Conceptually, although a single miRNA might interact with different mRNAs and could induce abnormal changes in the environment, this genetic transfer may cause a huge impact on the physiologic and phenotypic state of the recipient cells.

The trafficking of MVs with a concealed cargo of biomolecules would not only affect the phenotypic state of surrounding cells but could also affect distant cells by facilitating tumor cell invasiveness [43]. For instance, microRNAs shuttled to recipient cells by tumor cell MVs have also been shown to downregulate the activity of key proteins participating in cell proliferation and apoptosis pathways, such as cyclin D1, Bcl-2 and Pten. This indicates that the transfer of microRNAs from tumor cells to surrounding tissue cells through MVs may modulate the tumoral milieu (Figure 2).

Therefore, tumor-derived MVs are a novel way to exchange genetic information between cells (neoplastic and non-neoplastic cells) and modify the milieu and phenotype of recipient cells. The delivery of MVs has the potential to lead to the horizontal epigenetic spread of aggressive phenotypes and to reprogram normal cells to enhance their capacity to become more supportive for tumor growth and invasion [37,39].

\section{Microvesicles in Glioblastomas}

There are relatively few data in the literature about MVs in GBMs, but it is well-documented that glioma cells have co-opted this effective mode of communication mediated by MVs to spread proliferative and invasive signals throughout neighboring cells. Al-Nedawi and colleagues showed that EGFR vIII overexpression in glio- 
Table 2. Components of microvesicle cargo.

\begin{tabular}{|c|c|c|c|}
\hline Genomic content & References & Proteomic content & References \\
\hline $\begin{array}{l}\text { mRNAs, ncRNAs, } \\
\text { microRNAs }\end{array}$ & $\begin{array}{c}\text { Valadi et al., } 2007 \text { [9] } \\
\text { Skog et al., } 2008 \text { [12] } \\
\text { Taylor et al., } 2008 \text { [11] } \\
\text { Li et al. } 2013 \text { [7] }\end{array}$ & $\begin{array}{c}\text { Exocarta of } 111 \text { proteins, } \mathrm{RT} \text {, } \\
\text { transmembrane \& cytoplasmic } \\
\text { proteins }\end{array}$ & $\begin{array}{c}\text { ExoCarta database } 2012^{*} \\
\text { Mathivanan et al., } 2012 \text { [13] }\end{array}$ \\
\hline $\begin{array}{l}\text { Pluripotent transcription } \\
\text { factor-related mRNAs }\end{array}$ & Ratajczak et al., 2006 [25] & $\begin{array}{c}\text { Mutant EGFRvIII, } \\
\text { EGFR }\end{array}$ & $\begin{array}{l}\text { Al-Nedawi et al., } 2008 \text { [22] } \\
\text { Al-Nedawi et al., } 2009 \text { [23] }\end{array}$ \\
\hline $\begin{array}{l}\text { Non-microRNAs, tRNAs, } \\
\text { vault RNAs, intronic repeats }\end{array}$ & Li et al., 2013 [7] & $\begin{array}{l}\text { Proteolipid protein (PLP), } \\
\text { Alix and flotillin }\end{array}$ & Trajkovic et al. 2008 [19] \\
\hline LncRNAs & Nilsson et al., 2009 [32] & Nogo B, Fas-L & D’Agostino et al., 2006 [50] \\
\hline Transposable elements & $\begin{array}{l}\text { Balaj et al., 2011[10] } \\
\text { Li et al., } 2013 \text { [7] }\end{array}$ & TRAIL & Lo Cicero et al., 2011 [53] \\
\hline mtDNAs & $\begin{array}{c}\text { Spees et al., } 2006 \text { [33] } \\
\text { Guescini et al., } 2010 \text { [44] } \\
\text { Balaj et al., } 2011 \text { [10] }\end{array}$ & ADAMTS-1,4,5 & Lo Cicero et al., 2012 [54] \\
\hline $\begin{array}{l}\text { ssDNAs, including gDNA } \\
\text { and cDNA }\end{array}$ & Balaj et al., 2011 [10] & Transcription factors (TFs) & $\begin{array}{c}\text { Bastida et al. } 1984 \text { [34] } \\
\text { Yu \& Rak, } 2004 \text { [35] } \\
\text { del Conde } \text { et al., } 2005 \text { [36] }\end{array}$ \\
\hline $\begin{array}{l}\text { rRNAs and cell cycle } \\
\text { related mRNA }\end{array}$ & Hong et al., 2009 [37] & Cytokines, interleukin-1 beta & Bianco et al., 2009 [47] \\
\hline siRNAs & Kosaka et al., 2010 [38] & Transferrin receptor & Johnstone et al., 2006 [39] \\
\hline snRNAs & Valadi et al., 2007 [9] & H1 histone protein & Schiera et al., 2013 [40] \\
\hline
\end{tabular}

* Note $_{1}$ : http://www.exocarta.org; Note 2 : ncRNA, non-coding RNA; lncRNA, long noncoding RNA; ssDNA, single stranded DNA; gDNA, genomic DNA.

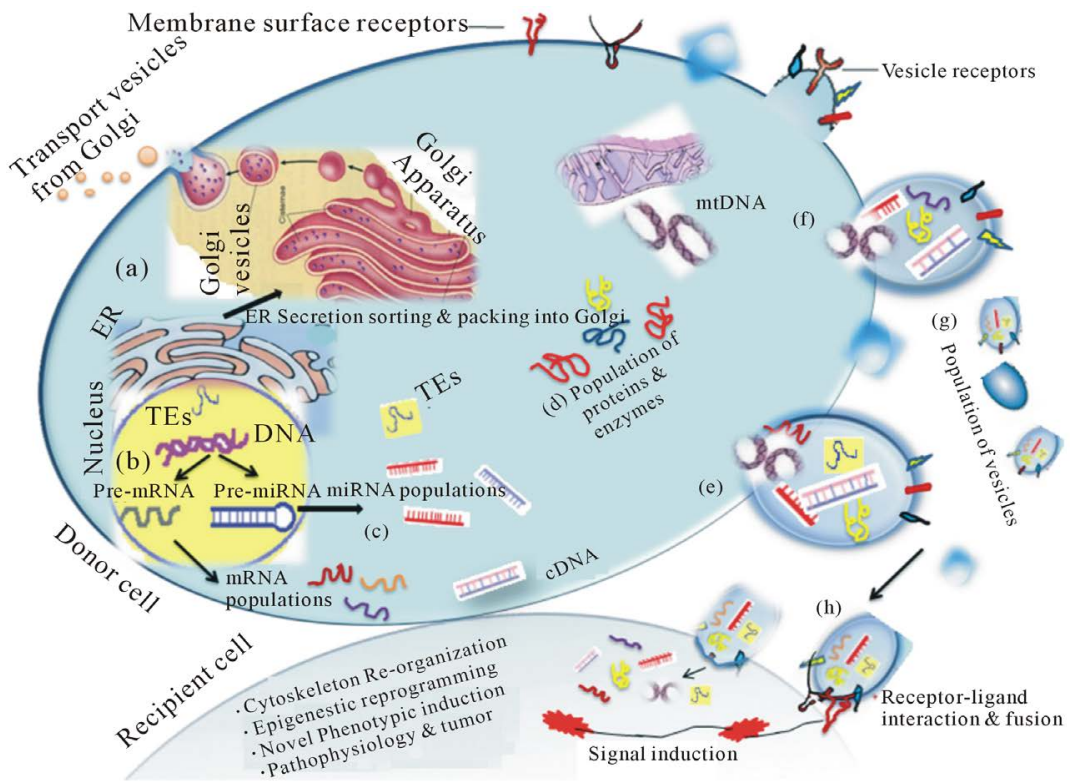

Figure 2. Schematic representation of sorting and packing of bioactive molecules into vesicles, their release and entry into recipient cells. (a) Release of Golgi vesicles containing secretory molecules including mRNAs and proteins (sorted by ER). (b) Biogenesis of pre-mRNA and pre-microRNA from nucleus and their transport to cytoplasm. (c) Maturation of mRNAs and microRNAs and sorting into diverse populations comprising normal and oncogenic RNAs. (d) Plethora of normal and oncogenic proteins. (e) and (f) Incorporation of biomolecules into vesicles under the influence of packing cell machinery. (g) Dissimilar population of released vesicles carrying different combinations of biomolecules. (h) Fusion of released vesicles to the recipient cell. Recipient cells and vesicles are interacted through common surface receptors. Receptor-ligand interaction and fusion with plasma membrane induces signal transduction via transmembrane proteins. Release of MV contents into cell further triggers cell signals that results into reorganization of cellular machinery. The epigenetic reprogramming results in novel cell phenotype and leads alteration in the tumor microenvironment (ER: endoplasmic reticulum; TEs: transposable elements; Pre-mRNA/pre-microRNA; premature mRNA/premature microRNA; mtDNA: mitochondrial DNA). 
ma cells stimulates the formation of lipid-raft-related MVs that can be shared between glioma cells, inducing an angiogenic switch [22]. In turn, this angiogenic signaling alters the expression of EGFRvIII-regulated genes, such as VEGF, BCL2 L1 (Bcl-xL), and CDKN1B (p27).

Microvesicles in GBM and normal astrocytes may contain mitochondrial DNA and single-stranded DNA (ssDNA) molecules, including both genomic DNA and cDNA that can be transferred to recipient cells $[10,44,45]$. Characterization of the microvesicles shed from glioblastoma cells has shown that they contain a variety of mRNA transcripts and non-coding RNAs related to cell proliferation, migration, angiogenesis, and immune repression [7,12]. The selective packing of miRNAs in glioma-derived MVs is thought to significantly enrich several functional pathways. For example, the MVs loaded with selected microRNAs in the U251 cell line are implicated in tumor growth, angiogenesis, cell death, cell proliferation, and tumor infiltration by targeting the glycosaminoglycan (GAG) biosynthesis pathway, $\mathrm{Ca}^{2+}$ reabsorption, and ECM-receptor interactions, respectively $[7,46]$.

As a disposal mechanism for cellular debris, MVs from brain tumor cells may also contain truncated and de-generative proteins in addition to cytokines, which may induce abnormal signals and have toxic effects after being taken up by normal cells. Bianco and colleagues described the severe injury of neural tissue induced by IL-1 $\beta$ released from MVs derived from activated microglia triggered by reactive astrocytes [47].

\section{Box 2. Summary of MVs in GBMs.}

Cargo: microRNAs, mitDNAs, ssDNAs, long ncDNAs, mRNAs, EGFRvIII.

Effects: cell proliferation, cell death, migration, tumor infiltration, angiogenesis, immune repression.

\section{Microvesicles in Low-Grade Astrocytomas}

There are very few data in the literature about MVs in low-grade astrocytomas. Guescini et al. showed that astrocytes can release microvesicles containing mitochondrial DNA. In this study, the authors indicated that exosomes as microvesicles carried mitochondrial DNA [44].

\section{Microvesicles in Oligodendrogliomas}

Microvesicle shedding in oligodendrogliomas was initially studied based on the assumption that oligodendrocytes have inhibitory effects on distant cells [48], and the majority of the proteins identified in oligodendrocytes that show inhibitory effects on neurons are components of cell membranes [49].

One early investigation revealed the presence of Nogo B (Neurite Outgrowth Inhibitor B) and Fas-L (Fas ligand) within oligodendroglioma vesicles, which have inhibitory effects on neurite outgrowth and trigger neuronal apoptosis [50]. Moreover, the overexpression of NogoB in tumor cells results in pro-apoptotic effects [51] due to the interaction of this ER-associated molecule with cytoplasmic anti-apoptotic proteins, such as Bcl-2 and Bcl-XL [52].

However, Fas-L activation allows tumor cells to escape from host immune surveillance and to create a cell-free environment that facilitates the growth of tumor cells [50]. TNF-related apoptosis-inducing ligand (TRAIL) is another component of MVs in oligodendrogliomas that is related to cell death [53]. It is assumed that both Fas-L and TRAIL cooperate to induce pro-apoptotic effects in normal brain cells through the shedding of these vesicles.

Microvesicles shed by oligodendrogliomas also play roles in cellular invasion, especially among aggrecan-rich extracellular matrices, by fusing part of the vesicle population with the surrounding cells $[53,54]$. Recently, Lo Cicero and colleagues reported that TIMP-3-sensitive aggrecanase activity was detected in MVs from oligodendrogliomas and that the aggrecanase activity in the shed MVs was due to ADAMTS enzymes (A Disintegrin and Metalloproteinase with Thrombospondin Motifs). Among these enzymes, the authors confirmed the presence of ADAMTS-1, ADAMTS-4 and ADAMTS- 5 by RT-PCR in MVs shed by oligodendroglioma cells. Furthermore, it was suggested that the aggrecanase activity was associated with the MV surface through interactions with heparan sulfate proteoglycan moieties. The presence of ADAMTSs in shed MVs presents a novel mechanism by which cells target these enzymes to lectican substrates in diverse extracellular matrices [54].

\section{Box 3. Summary of MVs in oligodendrogliomas}

Cargo: mRNAs, microRNAs, Nogo B, FAS-L, TRAIL, ADAMTS motifs.

Effects: trigger apoptosis, tumor growth and invasion, escape from immune surveillance.

\section{Microvesicles in Medulloblastomas}

Thus far, there are few data in the literature about MVs in medulloblastomas. In 2009, Graner et al. first reported exosomes produced from medulloblastoma cell lines. These exosomes had the same biochemical and physical properties as observed in other primary brain tumor exosomes, namely, the size, density, canonical heat shock protein content, acetylcholinesterase activity, and isoelectric points [55]. Later, Epple and colleagues described high percentages of nuclear proteins in medulloblastoma exosomes as well as proteins involved in transcriptional regulation that harbor nucleic acid-binding properties 
[56]. These authors also revealed that, in MBs, exosomes contain other components that play roles in cell proliferation, migration and immune responses. Further evaluation lead to the identification of a transcription factor (TF) within these exosomes, namely hepatocyte nuclear factor 4-alpha (HNF4 $\alpha$ ) [56]. HNF4 $\alpha$ is a member of a nuclear receptor superfamily associated with hepatocyte differentiation during embryogenesis, and dysregulation of this TF is associated with hepatocellular carcinoma (HCC) development via the induction of tumor growth, loss of epithelial morphology, and metastasis $[56,57]$. HNF4 $\alpha$ expression is usually dysregulated in tumors [58], and it exhibits a tumor suppressor effect in medulloblastoma cell lines [56].

The nucleic acid content of tumor MVs in medulloblastoma also contains high levels of specific coding and non-coding RNAs and DNA, mutated and amplified oncogene sequences and transposable elements [10]. Medulloblastoma cell lines that had genomic amplification and high-expression levels of the c-MYC oncogene (frequently amplified in MBs) were found to have a high level of exoDNA and exoRNA within their microvesicles. Thus, monitoring the levels of these ribonucleic acids as biomarkers in the serum or cerebrospinal fluid of patients with MBs may indicate c-MYC oncogene amplification [10].

\section{Box 4. Summary of MVs in medulloblastomas.}

Cargo: nuclear proteins, HNF4 $\alpha$ transcription factor, mRNAs, microRNAs, DNAs

Effects: cell proliferation, cell migration, immune surveillance, tumor growth, metastasis

\section{Perspectives}

As stated, there are few data regarding microvesicles in gliomas. Indeed, we did not find studies that addressed the participation of MVs in certain types of gliomas, such as pilocytic astrocytomas, anaplastic astrocytomas and ependymomas, despite a thorough search of the literature. Consequently, this is an open field that is yet to be explored and investigated. Nonetheless, there are several aspects of this novel mode of cell communication that remain obscure, and we can expect intensive research on tumor-derived MVs in the near future. A better understanding of the participation of MVs in the regulation of key cancer pathways will offer new insight into tumor pathogenesis and the putative mechanisms of developing multidrug resistance by cancer cells. This may be helpful in developing new strategies for novel therapies against these infiltrative CNS tumors, particularly in glioblastomas, the most lethal tumor type in humans.

\section{Acknowledgement}

We thank American Journal Experts for excellent editorial assistance and English review.
This work was supported by FAPESP (Sao Paulo Research Foundation, Proc. No. 12/24574-3), CAPES (Coordination for the Improvement of Higher Education Personnel) and FAEPA (Foundation for Supporting Teaching, Research and Assistance from Hospital of Clinics at Faculty of Medicine of Ribeirão Preto, University of São Paulo).

\section{Conflict of Interest Statement}

None declared.

\section{REFERENCES}

[1] D. N. Louis, H. Ohgaki, O. D. Wiestler, W. K. Cavenee, P. C. Burger, A. Jouvet, B. W. Scheithauer and P. Kleihues, "The 2007 WHO Classi Wcation of Tumours of the Central Nervous System,” Acta Neuropathologica, Vol. 114, No. 2, 2007, pp. 97-109. http://dx.doi.org/10.1007/s00401-007-0243-4

[2] M. J. Riemenschneider and G. Reifenberger, "Molecular Neuropathology of Low-Grade Gliomas and Its Clinical Impact," Advances and Technical Standards in Neurosurgery, Vol. 35, 2010, pp. 35-64. http://dx.doi.org/10.1007/978-3-211-99481-8 2

[3] S. Mueller and S. Chang, "Pediatric Brain Tumors: Current Treatment Strategies and Future Therapeutic Approaches," Neurotherapeutics, Vol. 6, No. 3, 2009, pp. 570-586. http://dx.doi.org/10.1016/j.nurt.2009.04.006

[4] G. Dhall, "Medulloblastoma," Journal of Child Neurology, Vol. 24, No. 11, 2009, pp.1418-1430. http://dx.doi.org/10.1177/0883073809341668

[5] B. György, T. G. Szabó, M. Pásztói, Z. Pál, P. Misják, B. Aradi, V. László, E. Pállinger, E. Pap, A. Kittel, G. Nagy, A. Falus and E. I. Buzás, "Membrane Vesicles, Current State-of-the-Art: Emerging Role of Extracellular Vesicles," Cellular and Molecular Life Sciences, Vol. 68, No. 16, 2011, pp. 2667-2688.

http://dx.doi.org/10.1007/s00018-011-0689-3

[6] C. D’Souza-Schorey and J. W. Clancy, "Tumor-Derived Microvesicles: Shedding Light on Novel Microenvironment Modulators and Prospective Cancer Biomarkers," Genes \& Development, Vol. 26, No. 12, 2012, pp. 12871299. http://dx.doi.org/10.1101/gad.192351.112

[7] C. C. Y. Li, S. A. Eaton, P. E. Young, M. Lee, R. Shuttleworth, T. D. Humphreys, G. E. Grau, V. Combes, M. Bebawy, J. Gong, S. Brammah, M. E. Buckland and C. M. Suter, "Glioma Microvesicles Carry Selectively Packaged Coding and Noncoding RNAs Which Alter Gene Expression in Recipient Cells,” RNA Biology, Vol. 10, No. 8, 2013, pp. 1-12. http://dx.doi.org/10.4161/rna.25281

[8] C. Thery, L. Zitvogel and S. Amigorena, "Exosomes: Composition, Biogenesis and Function," Nature Reviews Immunology, Vol. 2, No. 8, 2002, pp. 569-579.

[9] H. Valadi, K. Ekström, A. Bossios, M. Sjöstrand, J. J. Lee and J. O. Lötvall, "Exosome-Mediated Transfer of mRNAs and microRNAs Is a Novel Mechanism of Genetic Exchange between Cells,” Nature Cell Biology, Vol. 9, 2007, 
pp. 654-659. http://dx.doi.org/10.1038/ncb1596

[10] L. Balaj, R. Lessard, L. Dai, Y.-J. Cho, S. L. Pomeroy, X. O. Breakefield and J. Skog, "Tumour Microvesicles Contain Retrotransposon Elements and Amplified Oncogene Sequences," Nature Communications, Vol. 2, No. 180, 2011. http://dx.doi.org/10.1038/ncomms1180

[11] D. D. Taylor, C. Gercel-Taylor and R. N. A. Micro, "Signatures of Tumorderived Exosomes as Diagnostic Biomarkers of Ovarian Cancer,” Gynecologic Oncology, Vol. 110, No. 1, 2008, pp. 13-21.

http://dx.doi.org/10.1016/j.ygyno.2008.04.033

[12] J. Skog, T. Würdinger, S. van Rijn, D. H. Meijer, .L Gainche, M. Sena-Esteves, W. T. Curry Jr., B. S. Carter, A. M. Krichevsky and X. O. Breakefield, "Glioblastoma Microvesicles Transport RNA and Proteins that Promote Tumour Growth and Provide Diagnostic Biomarkers," Nature Cell Biology, Vol. 10, No. 12, 2008, pp. 14701476. http://dx.doi.org/10.1038/ncb1800

[13] S. Mathivanan, C. J. Fahner, G. E. Reid and R. J. Simpson, "ExoCarta. 2012: Database of Exosomal Proteins, RNA and Lipids,” Nucleic Acids Research, Vol. 40, No. 1, 2012, pp. D1241-D1244. http://dx.doi.org/10.1093/nar/gkr828

[14] D. Pilzer, O. Gasser, O. Moskovich, J. Schifferli and Z. Fishelson, "Emission of Membrane Vesicles: Roles in Complement Resistance, Immunity and Cancer," Springer Seminars in Immunopathology, Vol. 27, No. 3, 2005, pp. 375-387. http://dx.doi.org/10.1007/s00281-005-0004-1

[15] J. Guduric-Fuchs, A. O’Connor, B. Camp, C. L. O’Neill, R. J. Medina and D. A. Simpson, "Selective Extracellular Vesicle Mediated Export of an Overlapping Set of microRNAs from Multiple Cell Types,” BMC Genomics, Vol. 13, 2012, p. 357. http://dx.doi.org/10.1186/1471-2164-13-357

[16] C. Théry, M. Ostrowski and E. Segura, "Membrane Vesicles as Conveyors of Immune Responses," Nature Reviews Immunology, Vol. 9, 2009, pp. 581-593. http://dx.doi.org/10.1038/nri2567

[17] D. J. Katzmann, C. J. Stefan, M. Babst and S. D. Emr, "Vps27 Recruits ESCRT Machinery to Endosomes during MVB Sorting,” The Journal of Cell Biology, Vol. 162, No. 3, 2003, pp. 413-423. http://dx.doi.org/10.1083/jcb.200302136

[18] M. Babst, D. J. Katzmann, W. B. Snyder, B. Wendl and S. D. Emr, "Endosome-Associated Complex, ESCRT-II, Recruits Transport Machinery for Protein Sorting at the Multivesicular Body,” Development Cell, Vol. 3, No. 2, 2002, pp. 283-289.

http://dx.doi.org/10.1016/S1534-5807(02)00219-8

[19] K. Trajkovic, C. Hsu, S. Chiantia, L. Rajendran, D. Wenzel, F. Wieland, P. Schwille, B. Brügger and M. Simons, "Ceramide Triggers Budding of Exosome Vesicles into Multivesicular Endosomes,” Science, Vol. 319, No. 5867, 2008, pp. 1244-1247. http://dx.doi.org/10.1126/science.1153124

[20] K. E. Rankin and L. Wordeman, "Long Astral Microtubules Uncouple Mitotic Spindles from the Cytokinetic Furrow,” The Journal of Cell Biology, Vol. 190, No. 1,
2010, pp. 35-43. http://dx.doi.org/10.1083/jcb.201004017

[21] V. Muralidharan-Chari, J. Clancy, C. Plou, M. Romao, P. Chavrier, G Raposo and C. D'Souza-Schorey, “ARF6Regulated Shedding of Tumor Cell-Derived Plasma Membrane Microvesicles," Current Biology, Vol. 19, No. 22, 2009, pp. 1875-1885.

http://dx.doi.org/10.1016/j.cub.2009.09.059

[22] K. Al-Nedawi, B. Meehan, J. Micallef, V. Lhotak, L. May, A. Guha and J. Rak, "Intercellular Transfer of the Oncogenic Receptor EGFRvIII by Microvesicles Derived from Tumour Cells,” Nature Cell Biology, Vol. 10, 2008, pp. 619-624. http://dx.doi.org/10.1038/ncb1725

[23] K. Al-Nedawi, B. Meehan, R. S. Kerbel, A. C. Allison and J. Rak, "Endothelial Expression of Autocrine VEGF upon the Uptake of Tumor-Derived Microvesicles Containing Oncogenic EGFR," The Proceedings of the National Academy of Sciences of the United States of America, Vol. 106, No. 10, 2009, pp. 3794-3799. http://dx.doi.org/10.1073/pnas.0804543106

[24] L. Pigati, S. C. Yaddanapudi, R. Iyengar, D. J. Kim, S. A. Hearn, D. Danforth, M. L. Hastings and D. M. Duelli, "Selective Release of microRNA Species from Normal and Malignant Mammary Epithelial Cells,” PLoS One, Vol. 5, No. 10, 2010, Article ID: E13515. http://dx.doi.org/10.1371/journal.pone.0013515

[25] J. Ratajczak, M. Wysoczynski, F. Hayek, A. Janowska-Wieczorek and M. Z. Ratajczak, "Membrane-Derived Microvesicles: Important and Underappreciated Mediators of Cell-to-Cell Communication,” Leukemia, Vol. 20, No. 9, 2006, pp. 1487-1495. http://dx.doi.org/10.1038/sj.leu.2404296

[26] M. Simons and G. Raposo, "Exosomes-Vesicular Carriers for Intercellular Communication," Current Opinion in Cell Biology, Vol. 21, No. 4, 2009, pp. 575-581. http://dx.doi.org/10.1016/j.ceb.2009.03.007

[27] S. Fujimi, H. Ogura, H. Tanaka, T. Koh, H. Hosotsubo, Y. Nakamori, Y. Kuwagata, T. Shimazu and H. Sugimoto, "Increased Production of Leukocyte Microparticles with Enhanced Expression of Adhesion Molecules from Activated Polymorphonuclear Leukocytes in Severely Injured Patients," Journal of Trauma-Injury Infection \& Critical Care, Vol. 54, No. 1, 2003, pp. 114-119; Discussion, pp. 119-120. http://dx.doi.org/10.1097/00005373-200301000-00014

[28] P. E. Rautou, A. S. Leroyer, B. Ramkhelawon, C. Devue, D. Duflaut, A. C. Vion, G. Nalbone, Y. Castier, G. Leseche, S. Lehoux, A. Tedgui and C. M. Boulanger, "Microparticles from Human Atherosclerotic Plaques Promote Endothelial ICAM-1-Dependent Monocyte Adhesion and Transendothelial Migration," Circulation Research, Vol. 108, No. 3, 2011, pp. 335-343.

http://dx.doi.org/10.1161/CIRCRESAHA.110.237420

[29] J. B. Fishman, J. B. Rubin, J. V. Handrahan, J. R. Connor and R. E. Fine, "Receptor-Mediated Transcytosis of Transferrin across the Blood-Brain Barrier," Journal of Neuroscience Research, Vol. 18, No. 2, 1987, pp. 299304. http://dx.doi.org/10.1002/jnr.490180206

[30] J. Salo, P. Lehenkari, M. Mulari, K. Metsikkö and H. K. Väänänen, "Removal of Osteoclast Bone Resorption Pro- 
ducts by Transcytosis," Science, Vol. 276, No. 5310, 1997, pp. 270-273.

[31] P. Tuma and A. Hubbard, "Transcytosis: Crossing Cellular Barriers,” Physiological Reviews, Vol. 83, No. 3, 2003, pp. 871-932.

[32] J. Nilsson, J. Skog, A. Nordstrand, V. Baranov, L. Mincheva-Nilsson, X. O. Breakefield and A. Widmark, "Prostate Cancer-Derived Urine Exosomes: A Novel Approach to Biomarkers for Prostate Cancer," British Journal of Cancer, Vol. 100, No. 10, 2009, pp. 1603-1607. http://dx.doi.org/10.1038/sj.bjc.6605058

[33] J. L. Spees, S. D. Olson, M. J. Whitney and D. J. Prockop, "Mitochondrial Transfer between Cells Can Rescue Aerobic Respiration," Proceedings of the National Academy of Sciences of the United States of America, Vol. 103, No. 5, 2006, pp. 1283-1288. http://dx.doi.org/10.1073/pnas.0510511103

[34] E. Bastida, A. Ordinas, G. Escolar and G. A. Jamieson, "Tissue Factor in Microvesicles Shed from U87MG Human Glioblastoma Cells Induces Coagulation, Platelet Aggregation, and Thrombogenesis,” Blood, Vol. 64, No. 1, 1984, pp. 177-184.

[35] J. L. Yu and J. W. Rak, "Shedding of Tissue Factor (TF)Containing Microparticles Rather than Alternatively Spliced TF Is the Main Source of TF Activity Released from Human Cancer Cells," Journal of Thrombosis and Haemostasis, Vol. 2, No. 11, 2004, pp. 2065-2067. http://dx.doi.org/10.1111/j.1538-7836.2004.00972.x

[36] I. Del Conde, C. N. Shrimpton, P. Thiagarajan and J. A. López, "Tissue-Factor-Bearing Microvesicles Arise from Lipids Rafts and Fuse with Activated Platelets to Initiate Coagulation,” Blood, Vol. 106, No. 5, 2005, pp. 16041611. http://dx.doi.org/10.1182/blood-2004-03-1095

[37] B. S. Hong, J. H. Cho, H. Kim, E. J. Choi, S. Rho, J. Kim, J. H. Kim, D. S. Choi, Y. K. Kim, D. Hwang and Y. S. Gho, "Colorectal Cancer Cell-Derived Microvesicles Are Enriched in Cell Cycle-Related mRNAs That Promote Proliferation of Endothelial Cells,” BMC Genomics, Vol. 10, No. 556, 2009, pp. 1-13. http://dx.doi.org/10.1186/1471-2164-10-556

[38] N. Kosaka, H. Iguchi, Y. Yoshioka, F. Takeshita, Y. Matsuki and T. Ochiya, "Secretory Mechanisms and Intercellular Transfer of MicroRNAs in Living Cells," Journal of Biological Chemistry, Vol. 285, No. 23, 2010, pp. 1744217452.

[39] R. M. Johnstone, "Exosomes Biological Significance: A Concise Review,” Blood Cells, Molecules and Disease, Vol. 36, No. 2, 2006, pp. 315-321. http://dx.doi.org/10.1016/j.bcmd.2005.12.001

[40] G. Schiera, C. M. Di Liegro, P. Saladino, R. Pitti, G. Savettieri, P. Proia and I. Di Liegro, “Oligodendroglioma Cells Synthesize the Differentiation-Specific Linker Histone H1 and Release It into the Extracellular Environment through Shed Vesicles,” International Journal of Oncology, Vol. 43, No. 6, 2013, pp. 1771-1776.

[41] M. A. Antonyak, B. Li, L. K. Boroughs, J. L. Johnson, J. E. Druso, K. L. Bryant, D. A. Holowka and R. A. Cerione, "Cancer Cell-Derived Microvesicles Induce Transformation by Transferring Tissue Transglutaminase and Fibro- nectin to Recipient Cells," Proceedings of the National Academy of Sciences of the United States of America, Vol. 108, No. 12, 2011, pp. 4852-4857. http://dx.doi.org/10.1073/pnas.1017667108

[42] A. Yuan, E. L. Farber, A. L. Rapoport, D. Tejada, R. Deniskin, N. B. Akhmedov and D. B. Farber, "Transfer of MicroRNAs by Embryonic Stem Cell Microvesicles,” PLoS ONE, Vol. 4, No. 3, 2009, Article ID: E4722. http://dx.doi.org/10.1371/journal.pone.0004722

[43] F. Collino, M. C. Deregibus, S. Bruno, L. Sterpone, G. Aghemo, L. Viltono, C. Tetta and G. Camussi, "Microvesicles Derived from Adult Human Bone Marrow and Tissue Specific Mesenchymal Stem Cells Shuttle Selected Pattern of MiRNAs," PLoS ONE, Vol. 5, No. 7, 2010, Article ID: E11803. http://dx.doi.org/10.1371/journal.pone.0011803

[44] M. Guescini, S. Genedani, V. Stocchi and L. F. Agnati, "Astrocytes and Glioblastoma Cells Release Exosomes Carrying mtDNA,” Journal of Neural Transmission, Vol. 117, No. 1, 2010, pp. 1-4. http://dx.doi.org/10.1007/s00702-009-0288-8

[45] K. E. van der Vos, L. Balaj, J. Skog and X. O. Breakefield, "Brain Tumor Microvesicles: Insights into Intercellular Communication in the Nervous System," Cellular and Molecular Neurobiology, Vol. 31, No. 6, 2011, pp. 949-959. http://dx.doi.org/10.1007/s10571-011-9697-y

[46] R. Sasisekharan, Z. Shriver, G. Venkataraman and U. Narayanasami, "Roles of Heparan-Sulphate Glycosaminoglycans in Cancer,” Nature Reviews Cancer, Vol. 2, No. 7, 2002, pp. 521-528. http://dx.doi.org/10.1038/nrc842

[47] F. Bianco, C. Perrotta, L. Novellino, M. Francolini, L. Riganti, E. Menna, L. Saglietti, E. H. Schuchman, R. Furlan, E. Clementi, M. Matteoli and C. Verderio, "Acid Sphingomyelinase Activity Triggers Microparticle Release from Glial Cells,” EMBO Journal, Vol. 28, No. 8, 2009, pp. 1043-1054. http://dx.doi.org/10.1038/emboj.2009.45

[48] P. Caroni and M. E. Schwab, "Two Membrane Protein Fractions from Rat Central Myelin with Inhibitory Properties for Neurite Growth and Fibroblast Spreading," Journal of Cell Biology, Vol. 106, No. 4, 1988, pp. 1281-1288. http://dx.doi.org/10.1083/jcb.106.4.1281

[49] J. W. Fawcett and H. M. Geller, "Regeneration in the CNS: Optimism Mounts,” Trends in Neurosciences, Vol. 21, No. 5, 1998, pp. 179-180. http://dx.doi.org/10.1016/S0166-2236(98)01241-7

[50] S. D’Agostino, M. Salamone, I. Di Liegro and M. L. Vittorelli, "Membrane Vesicles Shed by Oligodendroglioma Cells Induce Neuronal Apoptosis,” International Journal of Oncology, Vol. 29, No. 5, 2006, pp. 1075-1085.

[51] Q. Li, B. Qi, K. Oka, M. Shimakage, N. Yoshioka, H. Inoue, A. Hakura, K. Kodama, E. J. Stanbridge and M. Yutsudo, "Link of a New Type of Apoptosis-Inducing Gene ASY/NogoB to Human Cancer,” Oncogene, Vol. 20, No. 30, 2001, pp. 3929-3936. http://dx.doi.org/10.1038/sj.onc.1204536

[52] E. Tagami, Y. Eguchi, M. Kinoshita, M. Takeda and Y. Tsujimoto, "A Novel Protein, RTN-Xs, Interacts with both Bcl-XL and Bcl-2 on Endoplasmic Reticulum and Reduces Their Anti-Apoptotic Activity,” Oncogene, Vol. 19, 
No. 50, 2000, pp. 5736-5746.

http://dx.doi.org/10.1038/sj.onc.1203948

[53] A. Lo Cicero, G. Schiera, P. Proia, P. Saladino, G. Savettieri, C. M. Di Liegro and I. Di Liegro, "Oligodendroglioma Cells Shed Microvesicles Which Contain TRAIL as Well as Molecular Chaperones and Induce Cell Death in Astrocytes," International Journal of Oncology, Vol. 39, No. 6, 2011, pp. 1353-1357.

[54] A. Lo Cicero, I. Majkowska, H. Nagase, I. Di Liegro and L. Troeberg, "Microvesicles Shed by Oligodendroglioma Cells and Rheumatoid Synovial Fibroblasts Contain Aggrecanase Activity," Matrix Biology: Journal of the International Society for Matrix Biology, Vol. 31, No. 4, 2012, pp. 229-233. http://dx.doi.org/10.1016/j.matbio.2012.02.005

[55] M. W. Graner, O. Alzate, A. M. Dechkovskaia, J. D. Keene, J. H. Sampson, D. A. Mitchell and D. D. Bigner, "Proteomic and Immunologic Analyses of Brain Tumor Exoso- mes,” FASEB Journal, Vol. 23, No. 5, 2009, pp. 15411557. http://dx.doi.org/10.1096/fj.08-122184

[56] L. M. Epple, S. G. Griffiths, A. M. Dechkovskaia, N. L. Dusto, J. White, R. J. Ouellette, T. J. Anchordoquy, L. T. Bemis and M. W. Graner, "Medulloblastoma Exosome Proteomics Yield Functional Roles for Extracellular Vesicles,” PloS ONE, Vol. 7, No. 7, 2012, Article ID: e42064. http://dx.doi.org/10.1371/journal.pone.0042064

[57] A. J. Watt, W. D. Garrison and S. A. Duncan, "HNF4: A Central Regulator of Hepatocyte Differentiation and Function,” Hepatology, Vol. 37, No. 6, 2003, pp. 1249-1253. http://dx.doi.org/10.1053/jhep.2003.50273

[58] N. L. Lazarevich, D. A. Shavochkina, D. I. Fleishman, I. F. Kustova, O. V. Morozova, E. S. Chuchuev and Y. I. Patyutko, "Deregulation of Hepatocyte Nuclear Factor 4 (HNF4) as a Marker of Epithelial Tumors Progression," Experimental Oncology, Vol. 32, No. 3, 2010, pp. 167171. 